\title{
Planned Country of Investigational Site
}

National Cancer Institute

\section{Source}

National Cancer Institute. Planned Country of Investigational Site. NCI Thesaurus. Code C98770.

The planned country within which the investigation, trial or study is taking place. 